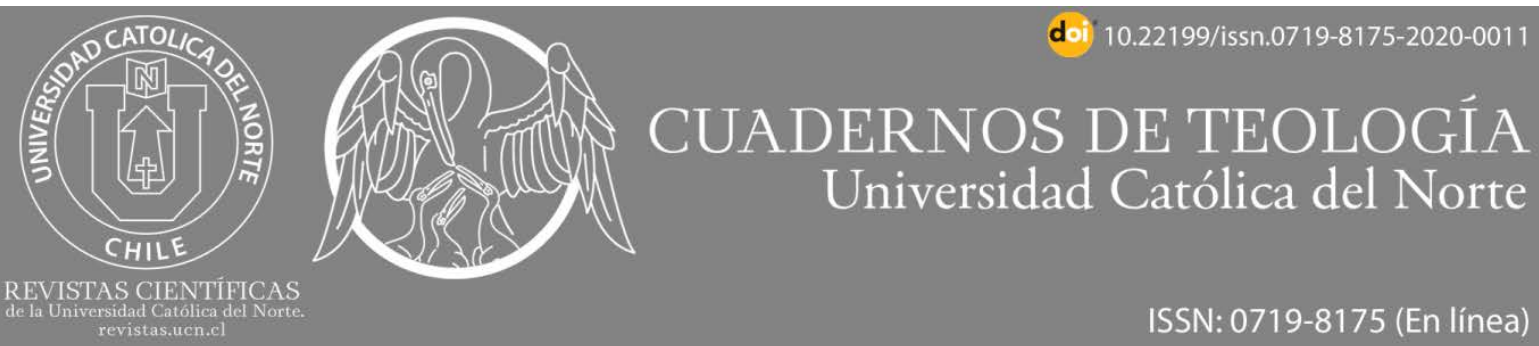

\title{
El signo del mar: una interpretación bíblico-teológica de Éx 14
}

\section{The sign of the sea: a biblical-theological interpretation Ex 14}

\author{
Carlos Alberto Vargas González1 (10) orcid.org/0000-0001-9746-6058 \\ 'Universidad de Medellín, Colombia. Docente. Maestría en Administración, U. Pontificia Bolivariana, Medellín. \\ cavargas@udem.edu.co \\ (cc) BY
}

\section{Resumen:}

Se tiene por objetivo realizar una interpretación biblico-teológica del milagro del mar, para lo cual se aborda Éxodo 14 desde una perspectiva histórico-crítica, y se hace una lectura teológica que propende por una comprensión del milagro del mar más allá de un intervencionismo mágico por parte de Dios. Para llevar a cabo esta investigación, se utiliza una metodología de tipo cualitativo-documental, pues se hace una revisión bibliográfica para justificar hermenéuticamente el acercamiento biblico-teológico a la perícopa en cuestión. Los principales hallazgos llevan a concluir que Éxodo 14 tiene varias capas redaccionales, lo cual esclarece las aparentes contradicciones; asimismo, se colige que el milagro no es un intervencionismo divino que rompe las leyes de la naturaleza, sino que es el descubrimiento, por la fuerza afirmativa de la fe, de la acción de Dios en el mundo.

Palabras Clave: Mar Rojo; Milagro; Método histórico-crítico; Creación.

\section{Abstract:}

The objective is aims to carry out a biblical-theological interpretation of the miracle of the sea, for which Exodus 14 is advocated from a critical historical perspective and a theological reading is made that provides for an understanding of the miracle of the sea beyond a magical interventionism from God. To carry out this research, a qualitative-documentary methodology is used, since a bibliographic review was made, to hermeneutically justify the biblical-theological approach to the perícopa in question. The main findings lead to the conclusion that Exodus 14 has several editorial layers, which clarifies the apparent contradictions; likewise, it is agreed that the miracle is not a divine interventionism that breaks the laws of nature, but is the discovery, by the affirmative force of faith, of God's action in the world.

Keywords: Red Sea; Miracle; Historical-critical method; Creation. 


\section{Introducción}

El paso del Mar de las Cañas ${ }^{1}$ es el suceso más conocido del Antiguo Testamento en el entorno actual. Cuando se interroga acerca de este acontecimiento a un contemporáneo, casi todos traen a la mente alguna imagen de una película que relata la vida de Moisés o que narra parte de la historia del pueblo de Israel.

En la actualidad, el Mar Rojo sigue siendo objeto de discusión desde muchos puntos de vista, por ejemplo, desde la geopolítica (Garduño García, 2019), la arqueología (Tallet, 2017), la geología (Batayneh, 2007), la topografía (Al-Arifi, Lashin y Al-Humidan, 2012; Bergoeing, 2015), la hidrología (Missimer, Hoppe-Jones, Jadoon, Li y Al-Mashharawi, 2014; Wood, 2011) y la sociología (Azaryahu, 2005).

De igual manera, hay un interés religioso por el Mar Rojo (Pinto, 2017) y es un tema obligado en cualquier manual acerca del Pentateuco o de la historia de Israel (Alexander, 1995; Blenkinsopp, 1999; Borgonovo, et al., 2012; Campbell y O'Brien, 1993 y 2005; Coogan, 2006; Couto, 2003; Fretheim, 1996; Galvagno y Giuntoli, 2014; García López, 2003; Settembrini, 2012).

De allí que hoy siga siendo relevante acercarse al milagro más grande de los judíos desde el punto de vista exegético. En lo que respecta a este artículo, se abordará Éxodo 14, que es la perícopa bíblica donde se narra el acontecimiento en cuestión, desde una perspectiva histórico-crítica, es decir, mostrando las diferentes capas que tiene el relato en sí. Cabe aclarar que, aunque la tendencia en la actualidad sea más destinada a leer los textos tal y como aparecen (Varo, 2016), el estrato redaccional de algunos textos sigue siendo un imperativo para superar ciertas contradicciones aparentes, sin dejar de lado que estas tradiciones siguen siendo consideradas hipótesis.

No obstante, si bien es innegable el valor de la investigación histórico-crítica, se precisa adentrarse mucho más en la dimensión teológica del milagro del Mar, dado que es un imperativo mirar las Sagradas Escrituras también desde esta perspectiva, tal como lo señaló acertadamente Benedicto XVI (2008):

Los Padres sinodales han afirmado con razón que el fruto positivo del uso de la investigación histórico-crítica moderna es innegable. Sin embargo, mientras la exegesis académica actual, también la católica, trabaja a un gran nivel en cuanto se refiere a la metodología histórico-crítica, también con sus más recientes integraciones, es preciso exigir un estudio análogo de la dimensión teológica de los textos bíblicos. (art. 34)

Por lo anterior, esta investigación pretende, por un lado, hacer un acercamiento a Éxodo 14 desde el punto de vista bíblico, mostrando diferentes estadios en el único texto que hoy aparece; por otro lado, se hace una interpretación teológica que propende por una comprensión del signo del mar más allá de un intervencionismo mágico por parte de Dios.

\footnotetext{
1 Es importante notar que la expresión "Mar Rojo" es convencional y proviene de los LXX y de la Vulgata; pero se trata de una traducción errónea: el hebreo suf indica la "caña", el "junco". La traducción de los LXX y la Vulgata se debe probablemente al hecho de que al menos en dos textos seguros (1 Re 9,26; Jer 49,21) la expresión se refiere al brazo oriental del Mar Rojo, el actual golfo de Aqaba.
} 
Para cumplir este cometido se utilizó una metodología de tipo cualitativodocumental, pues se hizo una revisión bibliográfica, para justificar hermenéuticamente el acercamiento biblico-teológico a Éxodo 14.

\section{Interpretación exegética del signo del mar}

\subsection{El texto que aparece en Éxodo 14}

El orden actual de la narración presenta, a grandes rasgos, la salida de Israel de Egipto así: los israelitas oprimidos quieren salir de la esclavitud, para conseguir el permiso del Faraón. Ellos ponen el pretexto de que deben ir al desierto a hacer sacrificios en honor de su Dios. Empero, el Faraón se niega a dejarlos salir, entonces vienen las nueve primeras plagas; no obstante, a pesar de esto, el corazón del soberano egipcios sigue endurecido. Posteriormente, Dios lanza la décima plaga: la muerte de los primogénitos, y en todas las casas de los egipcios había muertos (Éxodo 12, 30); viendo tal catástrofe, el mismo Faraón manda a llamar a Moisés y a Aarón durante la noche, y les ordenó que salieran a dar culto a YHWH, y el mismo pueblo egipcio instigaba a los israelitas para que salieran (Éxodo 12, 31 33). En la narración de este texto cabe señalar la existencia de dos versiones sobre la salida: una que habla de expulsión y otra de la huida de los israelitas.

Ahora bien, en lo que respecta específicamente a Éxodo 14, Ska (2001, pp. 109-110) lo divide en tres partes: $1-14 ; 15-25 ; 26-31$. La primera parte describe la crisis: la orden de YHWH, la persecución de los egipcios y el desespero del pueblo; las otras dos describen la resolución: la orden de YHWH a Moisés para que extienda la mano sobre el mar, la actuación del ángel, de la columna de nube y del viento del este, el milagro, la muerte de los egipcios y la fe del pueblo en YHWH y en su siervo Moisés. Cada una de las tres partes corresponde a un tiempo y a un lugar precisos: 1-14 se desarrolla antes de la noche, en el desierto, entre los egipcios y el mar; la escena de 15-25 tiene como lugar el mar y como tiempo la noche; $y$, finalmente, 26-31 describe los acontecimientos del alba en la otra orilla del mar.

Teniendo esta breve esquematización del texto, se puede pasar a una explicación de los versículos (Alonso Schökel, Mateos, Benito, Gil Modrego y Múgica, 1970; Alonso Schökel, s.f.).

1-4: La historia comienza con un discurso del Señor y posee un mandato muy claro: "Di a los israelitas" (v. 2a). El procedimiento proyecta los sucesos a su lugar de arranque, ubicándolos en un puesto geográfico bien preciso (v. 2b). Viene luego el anuncio del endurecimiento del corazón del Faraón y la manifestación de la gloria de YHWH a costa del máximo jefe de Egipto y de su ejército. Por último, una frase escueta muestra la ejecución del mandato: "Así lo hicieron" (v. 4b).

5-9: El cumplimiento del anuncio hecho en v. 4 viene presentado en estos versículos, pero lo desarrolla de dos maneras diversas: a) 5-7 es una reflexión humana del Faraón: "¿Qué es lo que hemos hecho dejando que Israel salga de nuestro servicio?" (v. 5b); ya en los dos siguientes versículos describe la preparación para la persecución; b) 8-9 es el cumplimiento del anuncio de una manera exacta: "Endureció Yahveh el corazón del Faraón y de Egipto" (v. 8a), el anuncio 
era: "endureceré"; esta era una total iniciativa de Dios que actúa en el corazón, mientras que en la primera (vv. 5-7) la iniciativa la toma el propio Faraón.

10-14: La vista inesperada del perseguidor introduce la primera crisis grave después de la salida: el temor, y tras este el clamor a YHWH (v. 10). Este miedo, fruto de la opción por ser libres, produce la protesta contra Moisés, pues:

...la libertad es riesgo, se gana y se defiende entre peligros, los israelitas -el hombre - se siente dividido entre el ansia de libertad y el deseo de seguridad, y en medio del riesgo añora la seguridad de la esclavitud, el descanso final en un sepulcro. (Schökel, Mateus \& Valverde, 1970, p. 270)

La libertad da miedo, porque es estar abandonado al peso de la propia responsabilidad: "El hombre es un ser condenado a ser libre. Condenado porque no se ha creado a sí mismo, y, sin embargo, por otro lado, libre porque una vez arrojado al mundo es responsable de todo lo que hace" (Sartre, 1985, pp. 68-69). Sí, es el miedo que sintió el pueblo de correr el riesgo de la libertad, por eso descargan toda la responsabilidad contra Moisés: “Acaso no había sepulturas en Egipto para que nos hayas traído a morir en el desierto? ¿Qué has hecho con nosotros sacándonos de Egipto?" (v. 12). Israel hubiera preferido morir seguro en la esclavitud en lugar de jugarse el peligro de la libertad. Frente a todas estas acusaciones, Moisés responde en la forma clásica de un Oráculo de salvación: invita a no temer, a estar firmes y a conservar la calma (v. 13), pues el mismo YHWH peleará por ellos (v. 14).

15-18: La pregunta del v. 15: “¿Por qué sigues clamando a mí?" dirigida a Moisés, supone la ausencia de una narración anterior que falta: quizás sea una oración de Moisés como en Éxodo 5:22-23; luego se repite el esquema del mandato: "Alza tu cayado, extiende tu mano sobre el mar y divídelo" (v. 16a), y del anuncio del endurecimiento del corazón de los egipcios; adicionalmente, viene la demostración de la gloria de Dios a costa de estos (vv. 1718).

19-20: Acá se interrumpe el curso narrativo normal, que sería la ejecución del mandato y el cumplimiento del anuncio. Aparece la presencia de Dios (nube y ángel) que se interpone entre los dos campamentos, componiendo una noche silenciosa.

21-22: se inicia el v. 21 con el cumplimiento del mandato del v. 16, es decir, Moisés extendió la mano, pero no fue él quien abrió el mar como lo había anunciado en el mandato, sino que fue Dios, por medio de un elemento cósmico: "Yahveh hizo soplar durante toda la noche un fuerte viento del Este, que secó el mar y se dividieron las aguas" (v. 21b). Se ve, pues, cómo en el silencio de la noche pelean dos elementos cósmicos: el agua y el viento; este último está al servicio de Dios (Cfr. Sal 104,4), el viento vence las aguas y estas se convierten en muralla protectora para el paso.

23-25: Los egipcios persiguen a los israelitas (v. 23), pero llega la mañana liberadora: la salvación llega por la mañana (Cfr. Sal 17,25), pues YHWH mira desde la columna de fuego y humo creando confusión en los egipcios, quienes desesperados quieren huir. 
26-29: Está el tercer mandato -sin anuncio-, ejecución y cumplimiento inmediatos: la muralla doble de las aguas se derrumbó sobre los egipcios. Así se ha demostrado la gloria de YHWH derrotando a los opresores y liberando a los israelitas.

30-31: Es la conclusión del relato, el pueblo es testigo de la acción de Dios, por eso cambia de actitud interna; el miedo de antes se transforma en respeto y reverencia, y la desconfianza se transforma en fe. De esta manera cree en YHWH y en Moisés su siervo.

\subsection{Aparentes contradicciones}

El texto, como se acabó de describir, lleva una secuencia normal, hasta el punto de que una lectura no detenida de este no muestra ni un problema. Sin embargo, un análisis pausado hará salir al camino algunas aparentes contradicciones: "El relato bíblico contiene una serie de contradicciones, incoherencias y detalles increíbles..." (Álvarez, 2002, p. 408).

A continuación, se mostrarán algunas de esas aparentes contradicciones.

\subsubsection{La decisión del Faraón, ¿acción de YHWH o recapacitación del Faraón?}

En el v. 4 YHWH anuncia a Moisés que endurecerá el corazón del Faraón para que los persiga, y este anuncio se hace efectivo en el v. 8; no obstante, el v. 5 muestra que la iniciativa la toma el propio Faraón reflexionando así: “QQué es lo que hemos hecho dejando que Israel salga de nuestro servicio?". Por la misma razón hay otra contradicción en el número del ejército, pues según el v. 6 el Faraón hizo enganchar su carro y llevó consigo todas sus tropas; se añade en el v. 7 que tomó 600 carros escogidos y todos los carros de Egipto montados por sus combatientes; y ya en el v. 9 dice que salieron todos los caballos, los carros del Faraón, con la gente de sus carros y su ejército.

\subsubsection{La actitud frente a sus perseguidores}

Hay una doble respuesta, según Ska (2001, p. 102), para que los israelitas reaccionen contra el miedo cuando ven a sus perseguidores:

i. En vv. 13-14 Moisés se dirige al angustiado pueblo pidiéndole que no tema, pues YHWH los salvará peleando por todos estos hombres que quieren ser libres.

ii. $\quad$ En v. 15 YHWH parece reprender a Moisés: “¿Por qué sigues clamando a mí? Di a los israelitas que se pongan en marcha". Aparece, entonces, la contradicción, ya que Moisés no estaba clamando a Dios, sino que estaba invitando al pueblo a la calma, entonces por qué YHWH le recrimina?; por otro lado, en vv. 13-14 se invitaba a la calma, y en v. 15 les dice que se pongan en marcha.

\subsubsection{La naturaleza del milagro:}

Según Ariel Álvarez (2002, pp. 409-411), el relato encierra tres versiones distintas del milagro de la liberación:

i. La salvación de la nube: la noche en la que el pueblo huyó el ángel de YHWH y una columna de nube se colocaron delante de este para guiarlo; cuando los egipcios los 
alcanzaron, se ubicaron detrás del pueblo (v. 19); de este modo, ocultaron a los hebreos y los perseguidores no los pudieron ver.

ii. El viento del Este: en medio de la noche empezó a soplar un fuerte viento del este que secó el mar (v. 21b), los egipcios acampan donde antes había agua; a la madrugada, Dios, desde la columna de fuego y de nube, provocó una inundación.

iii. Las murallas de agua: Moisés levanta el bastón sobre las aguas, al hacerlo el mar se divide por la mitad y sus aguas forman una muralla a la derecha y a la izquierda. Los israelitas entran, detrás de ellos los egipcios, quienes son arrebatados por las aguas después de que Moisés ejecuta la nueva orden de tender la mano.

\subsubsection{La muerte de los egipcios}

Ska (2001, pp. 105-106), haciendo un análisis de este fenómeno, descubre lo siguiente:

i. ¿Las aguas o el mar? Según el v. 26 los israelitas ya están a la otra orilla, en ese momento YHWH le pide a Moisés que vuelva su mano sobre el mar para que las aguas arrasen a los egipcios; Moisés cumple el mandato en vv. 27-28; sin embargo, el v. 27 no habla del retorno de las aguas (vv. 26 y 28), sino del mar. También hay una diferencia temporal, debido a que cuando YHWH le ordenó a su siervo extender la mano no dice que las aguas retornarán al alba; y el v. 27 afirma que el mar vuelve a su lecho al rayar el alba.

ii. ¿Cómo perecieron los egipcios? Según el v. 27 al amanecer el mar volvió a su estado natural, dicho versículo hay que ponerlo en relación con el v. 21b, donde es YHWH quien retiró el mar mediante un recio viento dejándolo seco, el mar vuelve al rayar el alba, y los egipcios quieren huir. Esta escena es difícil de conciliarla con la de los vv. 26.28-29, pues aquí es Moisés quien, por orden divina, abre las aguas formando estas una muralla, cuando el pueblo pasa nuevamente actúa Moisés extendiendo su mano; las aguas forman dos muros, los cuales se desploman sobre los egipcios quedando estos sumergidos. Por tanto, en un caso el mar vuelve a su lugar mediante un movimiento horizontal, por otro lado las aguas caen mediante un movimiento vertical; por una parte, los egipcios huyen (vv. 25.27), por otra, los persiguen (vv. 23.28) incluso en los momentos en que las aguas los cubren; no obstante "no cabe duda de que los perseguidores egipcios se ahogaron (...), y al describir cómo ocurrió esto el autor invoca tanto un repentino viento huracanado (v. 10) como la condensación de las aguas formando un dique (v. 8)" (Blenkinsopp, 1999, p. 209).

Estas son algunas contradicciones que ofrece el texto o, mejor dicho, más que contradicciones, serían diferentes versiones de un mismo acontecimiento, lo cual lleva a preguntarse lo siguiente: ¿cuál es la verdad de los hechos? y ¿a qué obedecen estas diversas versiones? 


\subsection{Varias tradiciones}

Joseph Blenkinsopp (1999) introduce claramente a la solución de las aparentes contradicciones:

El relato en prosa de la liberación en el mar (Éx 14) puede ser leído como una narración completa y bastante coherente, pero es claro que el narrador ha combinado dos estratos narrativos que representan dos versiones distintas de cómo tuvo lugar la liberación. (p. 206)

Según este autor estas dos versiones corresponden: una a la escuela sacerdotal $(\mathrm{P})$ y otra a la versión alternativa. En P está la mayor parte de los versículos: vv. 15-18.21-23.26-29; el resto está en la versión alternativa.

Por su parte, Luis Alonso Schökel (s.f.) sostiene lo siguiente: "El reparto comúnmente aceptado es así, con algunas dudas: J. 5b.6.9aa.10ba.11-14.19b.21ab.24.25b.27abb.30-31. E. 5a.7.19a.25a. P. 1-4.8.9abb.15-18.21aab.22-23.26.27a.28-29" (p. 181).

Ska (2001, pp. 108-109), por otro lado, distingue dos versiones, la J y la $\mathrm{P}$, al primer relato lo denomina "La desecación de las aguas", al segundo lo llama "La división de las aguas". A continuación se expondrán estas versiones.

\subsubsection{La versión Yahvista "J"}

Acá el Faraón es quien toma la iniciativa, esto obedece a que el autor Yahvista es "más psicológico: hace notar los sentimientos del Faraón y de los egipcios" (Auzou, 1996, p. 193), los cuales persiguen a los israelitas y los alcanzan por la tarde en la orilla del mar. La nube interviene, se mueve impidiendo que los perseguidores se aproximen más, pero también se interpone el ángel de YHWH: "Según J, Yahveh se manifiesta de dos maneras: (a) el ángel de Dios (V. 19a) y (b) la columna de nube (v. 19b) (...) Dicha posición supone protección para Israel" (Farmur, Levoratti, Eugnue y Dungan, 1999, p. 392).

Esta situación dura toda la noche, YHWH hace soplar un recio viento del este que seca el mar (v. 21b). Al día siguiente, de madrugada, YHWH, desde la columna de fuego y nube, siembra el pánico entre los egipcios y entorpece la rueda de sus carros (vv. 24-25). Al apuntar el día las aguas vuelven a su lecho y el Señor sumerge en ellas a los egipcios (v. 27b). El resultado es que Israel reconoce la acción de su Dios y cree en él y en su siervo Moisés (vv. 30-31).

\subsubsection{La versión sacerdotal "P"}

Los israelitas habían salido de Sukkot, "pero una orden de Dios los hace volver para acampar frente al pi-ha-jirot, entre Migdol y el mar y frente a Baal-sefon (VV1-4). (...) P situará el milagro del mar al noreste del delta del Nilo, a lo largo de la costa mediterránea" (Levoratti, Tamez y Richard, 2003, p. 451).

En este relato no es el mismo Faraón quien toma la iniciativa de perseguir a los israelitas, sino que es una acción directa de Dios que endurece su corazón (el del Faraón) para que salga a la persecución del pueblo. Sale con todos los carros, los caballos, con la 
gente de los carros y el ejército (vv. 8-9a), y los alcanzan. El Señor le da una instrucción a Moisés de lo que tiene que hacer él y el pueblo (vv. 15-18), ya no es el momento de clamar, sino de actuar, hay que ponerse en marcha; el siervo tiene que extender su mano sobre el mar para que se divida y así puedan pasar a pie enjuto; en cambio, como Egipto tiene el corazón endurecido, los perseguirán y el Señor mostrará su gloria. Moisés ejecuta el mandato en v. 21a, las aguas se parten y los hombres que antes estaban esclavos pasan a la libertad por medio de la muralla de agua. Cuando llegan al otro lado del mar -cosa que no dice pero que se da por entendida- YHWH le pide a Moisés que extienda nuevamente su mano sobre el mar (v. 26), quien ejecuta la orden en v. 27a, y efectivamente las aguas retroceden y no escapa "ni uno solo" de los egipcios.

Las antecedentes son las dos versiones más importantes del milagro del mar, cada una con unos matices y unos materiales muy distintos. Sin embargo, debe quedar claro que "el milagro del mar se produjo una sola vez y está vinculado al éxodo-huida y a Moisés. Pero, a causa de esta dualidad de tradiciones y del trabajo redaccional, no sabremos nunca dónde tuvo lugar" (De Vaux, 1971, p. 367).

En definitiva, el capítulo 14 del Éxodo da el testimonio de un acontecimiento donde Dios actuó a favor de su pueblo, y es por esta actuación concreta en la historia particular de unos hombres unidos en una misma experiencia, la que los lleva a dar el paso de la fe; no en vano el relato termina afirmando: "Y viendo Israel la mano fuerte que Yahveh había desplegado contra los egipcios, temió el pueblo y creyeron en Yahveh y en Moisés, su siervo" ( $v$. 31).

\section{Interpretación teológica del signo del mar}

\subsection{La fe como causa y efecto del milagro del mar}

Si bien el acontecimiento del mar es recordado por gran parte de la humanidad, para nadie significa ni ha significado tanto como para Israel. Este prodigio es tan influyente en este pueblo, que se ha convertido en una verdad de fe; y no es para menos, pues los israelitas des-cubrieron la acción de YHWH en su historia particular, de un Dios que los sacó de la esclavitud a la libertad, es por esta razón que :

la afirmación 'Yahveh sacó a Israel de Egipto' tiene el carácter de una profesión de $\mathrm{fe}$, dondequiera que se le pronuncie. Lo encontramos en todos los estratos de la tradición hasta Dan 9, 15 y en los contextos más diversos; es tan frecuente que será designada la profesión primitiva de Israel. (von Rad, 1972, p. 230).

Es un acontecimiento histórico interpretado por la fuerza afirmativa de la fe, la cual hace des-cubrir la intervención divina en la liberación del yugo impuesto por Egipto al pueblo elegido. Es la fe la que hace que:

... Ios Israelitas proclamen la acción del Señor que hizo subir a Israel de Egipto (Am 2,$10 ; 3,1 ; 9,7 ;$ Os 12,14, etc.; en total 41 veces) (...). Muy frecuentemente en forma sinónima: que hizo salir a Israel (Ex 20,2; 32,11-12; etc.; en total 83 veces) (...). Este 
acontecimiento siempre recordado, es la experiencia fundacional de la alianza, la matriz del lenguaje de la salvación. (Berder, et al., 1998, p. 7)

Esta salvación se realiza en la historia, que debe ser siempre llevada en la memoria. Así lo entendían los israelitas:

Los egipcios nos maltrataron, nos oprimieron y nos impusieron dura servidumbre. Nosotros clamamos a Yahveh Dios de nuestros padres, y Yahveh escuchó nuestra voz; vio nuestra miseria, nuestras penalidades y nuestra opresión, y Yahveh nos sacó con mano fuerte y tenso brazo en medio de gran terror, señales y prodigios. (Deuteronomio 26, 6-8)

Hay otro texto muy significativo, y es precisamente Josué 24:1-13, que es el recuerdo de la historia que ha vivido Israel; concretamente en este punto dice:

Saqué a vuestros padres de Egipto y llegasteis al mar, los egipcios persiguieron a vuestros padres con sus carros y sus guerreros hasta el mar de Suf. Clamaron entonces a Yahveh, el cual tendió unas densas nieblas entre vosotros y los egipcios, e hizo volver sobre ellos el mar, que los cubrió. Visteis con vuestros propios ojos lo que hice con Egipto. (Josué 24, 6-7)

En estos textos se entiende el sentido profundo de historia que tiene Israel, pues en la perícopa citada del Deuteronomio la persona que pronuncie esta profesión lo debe hacer en primera persona del plural, como si lo que recordaran lo hubieran vivido personalmente, llega hasta el extremo que parece ser que recordar fuera vivir. Sirva de paso la aclaración según la cual etimológicamente re-cordar es volver a poner en el corazón: el pueblo pone en el corazón lo que han vivido. Algo similar ocurre con la expresión de Josué: "Visteis con vuestros propios ojos lo que hice con Egipto". Para Israel el pasado parece actualizarse.

En efecto, la liberación de Israel solo es comprensible como milagrosa desde la fe, pues quizás las personas que vivieron el acontecimiento como tal, no des-cubrieron inmediatamente la acción de YHWH, porque fue:

...una acción silenciosa de Yahveh, en la que Israel fue también el objeto mudo de la intervención divina. Más tarde (...) desarrollaron este elemento confesional hasta convertirlo en una narración, introdujeron un buen número de palabras (...). Por muy importantes que ellas sean, el acontecimiento es siempre la realidad fundamental. El antiguo Israel no espiritualizó nunca este acontecimiento. (von Rad, 1972, p. 230)

Como lo expresa von Rad, el hecho histórico de la liberación de Egipto solo es comprensible como una "intervención" divina mucho tiempo después, cuando su pueblo volvió la mirada al pasado y des-cubrió allí, desde la fe, la acción de YHWH su Dios. Esto obedece a que cuando el pueblo estaba viviendo el milagro del mar en cuanto estaban en "la sucesión de los presentes" (Camus, 1973, p. 169) inmediatos, no fueron sensibles a la providencia en su espacio y tiempo concretos, en cambio las próximas generaciones, debido a que estaban alejados del acontecimiento real y así lo podían ver en su conjunto, hicieron la interpretación histórica de la fe. 


\subsection{Necesidad de una teología del milagro}

Como se sustentó anteriormente, el milagro pudo haber sucedido de diferentes maneras, pero ¿qué es lo realmente importante en esta diversidad de versiones? Lo relevante, en términos generales, es el hecho de que, en los diferentes estratos redaccionales, se da cuenta de que Dios actuó a favor de un pueblo concreto:

Aunque las cosas sucedieran de una manera o de otra, en forma más o menos natural, más o menos excepcional, lo importante es que el acontecimiento fue comprendido desde dentro, que la fe 'vio' cuál era el poder que estaba realmente actuando, el poder incomparable y único de Dios. De ahí nació 'un asombro que ya nunca se podrá borrar' (M. Buber, citado en Auzou, 1996, pp. 197-198)

Lo que importa, en el fondo, es el asombro, por la fuerza de la fe, que produjo este acontecimiento en la historia de ese pueblo concreto. No obstante, los hechos en sí deben ubicarse en una interpretación teológica adecuada del milagro, de tal manera que puedan sacarse las consecuencias prácticas para el aquí y el ahora, encontrando la manera adecuada de "expresar hoy lo de siempre, de suerte que hable a nuestra cultura y haga sentir su efecto en nuestra realidad" (Torres, 1996, p. 266).

Es por ello que durante la historia ha resultado imperiosa una teología adecuada de los milagros, dadas las dificultades con las que se encuentra el hombre para interiorizar esta categoría adecuadamente (Erdozain, 2002; Hyslop, 1983; Morales, 1970); no en vano, es muy conocida la expresión de un clásico teólogo, que sigue teniendo su pertinencia: "No se puede utilizar la luz eléctrica y el aparato de radio, exigir en caso de enfermedad tratamientos médicos y clínicos modernos y creer, al mismo tiempo, en el mundo de los espíritus y de los milagros del Nuevo Testamento" (Bultmann, 1973, p. 110) o, en este caso, del Antiguo Testamento.

De allí que las descripciones literarias del milagro del mar puedan dar lugar a una comprensión determinada del hecho en sí, que llegarían incluso a afectar la imagen de Dios, pues, ¿cómo entender el significado de la presencia de Dios en la nube, en el ángel y en el mismo Moisés?, ¿cómo entender que un Dios bueno devuelva bruscamente las aguas sobre los egipcios haciéndolos morir?

Por ello, para hacer una interpretación del milagro del mar, se tendrá como ruta de navegación dos presupuestos: Dios crea un mundo finito y es un Dios bueno que hace salir el sol sobre buenos y malos (Cfr. Mateo 5,45).

\subsection{Dios crea un mundo finito}

Si Dios decide crear -si se permite utilizar este lenguaje- él "tenía" que crear un mundo distinto de sí mismo, no "podía" crear algo perfecto, simplemente porque es absurdo: "Si Dios crea, no puede crearse a sí mismo: tiene que crear un mundo finito" (Torres, 1986, p. 152). Ahora bien, si lo crea a modo de ser finito, este, por naturaleza, tiene que ser imperfecto, pues la finitud siempre es carencia, porque depende de una perfección.

Adicionalmente, si Dios creó el mundo finito, él no "puede" intervenir empíricamente en este, porque sería contradecirse, ya que lo hubiera podido hacer mejor y 
no lo quiso hacer; sería hacer de la creación un reloj y de sí mismo un relojero, que arregla cada cosa que se daña, o que manipularía el reloj a su antojo (abrir el mar); si fuera así, la creación no sería más que una marioneta manejada al antojo del Creador.

En efecto, Dios hizo el mundo perfecto, finitamente hablando, con unas leyes que lo regulan y lo hacen funcionar, pero hay que tener presente que "la creación no es un acto puntual que nos ponga en el ser y luego nos abandone a la inercia de la propia perduración (...) Sin la viva y perenne presencia del actor-creador, no seríamos, sencillamente" (Torres, 1986, p. 83). Esto es, la creación toda está siendo conducida por Dios, mas él no "puede" manipularla a su antojo.

Se podrá objetar lo anterior haciendo uso del atributo de "todopoderoso", pero es menester tener presente lo siguiente:

Si entendemos estas expresiones (Todopoderoso, lo que quiere lo hace) en sentido literal, Dios es entonces un ser, el mayor de todos, que puede hacer todo cuanto quiere, con lo cual se sobreentiende que existen multitud de cosas que Dios no quiere hacer, y este es un concepto absurdo, fruto de nuestra imaginación, que nos hunde en un total confusionismo. El significado real de la Omnipotencia es que Dios es el poder del ser en todo lo que es, trascendiendo infinitamente cada poder particular, pero actuando al mismo tiempo como su fondo creador (...). Un poder que, en términos ontológicos, es la infinita resistencia contra el no-ser y la eterna victoria sobre él (Tillich, 1970, pp. 144145).

Aplicando esta interpretación de la Omnipotencia a Éxodo 14, se comprende que Dios no abrió el mar rompiendo las leyes que él mismo creó. Además, afirmar que lo hizo trae una consecuencia nefasta: Dios puede hacer tantas cosas y no las hace; por ejemplo, ¿por qué a los israelitas sí les abrió el mar y por qué aquí y ahora no abre las puertas para que el ser humano huya de las diferentes esclavitudes actuales?, ¿por qué no detiene el mar cuando invade ciudades enteras dejando miles de muertos?, ¿por qué no detiene tantos huracanes y desastres naturales que hacen correr mares de lágrimas en el mundo entero?

\subsection{Dios hace salir el sol sobre buenos y malos}

Según la teología Joánica Dios es amor (1 Jn 4, 8.16), de lo cual se desprende su atributo de bondad. Ahora bien, un Dios que practique misericordia con unos sí y con otros no, no es bueno: es injusto, ya que tiene preferencias, y se debe recordar que Dios no hace acepción de personas (Cfr. Hch 10,34). Entonces, ¿cómo entender que por un mandato divino los egipcios mueran?

Para hacer claridad a esta cuestión, Vaux (1971, pp. 368-369) trae una teoría que propone que el milagro no es el paso del mar por parte de los israelitas, sino la destrucción de los egipcios; y esta está basada en el antiquísimo canto de María recogido en Éxodo 15, de lo cual también se da cuenta en Deuteronomio 11, 4 y en Josué 24, 7. De esto se ha deducido que hubo un choque militar en el que los israelitas vencieron a la caballería del Faraón que los perseguía. Los israelitas pusieron entre ellos y los egipcios el "mar", que estaba anormalmente bajo, o incluso seco, por condiciones atmosféricas excepcionales. Los carros egipcios se metieron en ese terreno húmedo y movedizo y se atollaron, 
constituyendo un blanco fácil para los arqueros israelitas. Como puede colegirse, en esta teoría no hay intervención empírica directa de Dios en contra de los egipcios.

Hay otra teoría que sostiene que hubo marea baja, un efecto natural producido por la luna, pues en cualquier punto terrestre, una masa elemental está sometida a la atracción ejercida por cada astro del sistema solar, que se denomina fuerza de marea. Quizás esto fue lo que pasó cuando el pueblo elegido llegó al mar: por efectos lunares había marea baja y pudieron pasar; cuando los egipcios se acercaron ya el mar estaba nuevamente normal. A lo mejor Israel aprovechó dos cosas para escapar: a) el permiso que les dio el Faraón -o la posible ocupación de los egipcios frente a la décima plaga que descuidaron a los esclavos y algunos escaparon-, y b) el efecto natural de la marea baja muy conocido empíricamente por Israel.

Realmente no se puede saber cómo fue en sí el milagro del mar, pero lo que sí se da por descartado es que Dios haya eliminado a los egipcios, pues iría en contra de su constitución ontológica que es amor.

Se han sacado dos conclusiones hasta el momento: a) Dios no interviene empíricamente abriendo el mar en sentido literal, y b) Dios no "puede" matar a los egipcios. Luego, ¿cuál fue la acción de Dios en el milagro del mar?

\subsection{Todo acontecimiento, desde la fe, puede ser un milagro}

Es usual que cuando muchos contemporáneos escuchan la categoría "milagro" inmediatamente la relacionan con un acontecimiento que rompe las leyes físicas creadas por Dios; por lo tanto, solo si ocurre algo que no sea explicable científicamente, hay milagro. Esta concepción es errada y bastante desvirtuada de lo que entiende la Sagrada Escritura por milagro.

Para dar una interpretación diferente a la categoría milagro, se requiere comprender que en la actualidad hay un consenso prácticamente unánime de que lo que constituye el núcleo determinante de todo es la autonomización (Torres, 2000): esta autonomía se da en la realidad física, que demostró que los astros no se movían por fuerzas superiores, sino que tenían una fuerza intrínseca que los hacía mover, todo obedece a unas leyes naturales. Autonomía en lo socio-político, ya que el reparto de la riqueza y de la autoridad no proviene de Dios, sino que es efecto de decisiones humanas. Autonomía en el comportamiento, ya las actitudes no son fruto de la acción de Dios o del demonio en la persona, sino que la psicología y los estudios neuronales demostraron que estas formas de proceder son producidas por el inconsciente, por la formación familiar, social y cultural o por cuestiones biológicas. Autonomía en la historia y en el devenir del cosmos, ya la historia no es la voluntad de Dios, sino construcción humana; igual el cosmos, ya este no está determinado por la acción de un ordenador supremo, sino que, naturalmente, va evolucionando.

En definitiva, el mundo, en general, es autónomo y su funcionamiento obedece a una serie de leyes o circunstancias (en el caso del hombre) que se pueden, en su mayoría, explicar. Por tanto, frente a esta concepción de lo que es el mundo y el hombre, no es viable pensar que ocurran milagros rompiendo la autonomía de la creación. 
Por otra parte, si se mira la Sagrada Escritura se cae en la cuenta de que el concepto milagro es algo mucho más profundo. La antigüedad entendía el universo en tres pisos: a) el mundo superior: donde habitan los dioses, b) la tierra: es la habitación de los hombres, y c) el mundo inferior: es el reino del mal. Es por ello que:

...entre los dioses y la tierra no hay una separación tal que elimine una intervención constante y directa de los dioses en la mansión humana (...). Obvio que los antiguos conocen el normal ciclo evolutivo de la naturaleza, pero en él reconocen la acción del poder divino. (Cardona, 2002, p. 75)

Es bastante interesante la cosmología antigua - de la cual Israel evidentemente no era la excepción-, pues gracias a ella se infiere qué es un milagro, que sería, escuetamente hablando, un hecho en el que el hombre des-cubre o re-conoce la acción de Dios, sin necesidad de violar las leyes de la naturaleza. El pueblo de Israel fue sensible para des-cubrir la acción de Dios en su historia particular.

Este es el gran milagro del mar: sin necesidad de que Dios interviniera empíricamente abriendo el mar y matando a los egipcios, ellos des-cubrieron que en este acontecimiento YHWH había actuado a favor suyo:

Para los judíos, el mayor milagro de la Biblia lo constituía el paso del mar de los Juncos (no el Mar Rojo, como suele afirmarse, sino el Mar de los Juncos, que es un pantano al norte del Mar Rojo). Todos los expertos actuales coinciden en que este hecho, y el subsiguiente hundimiento del ejército egipcio, pueden explicarse por el fenómeno natural de las mareas y los vientos, que fueron verdaderamente 'providenciales' para los israelitas. A pesar de todo, éste sigue siendo el gran milagro del Antiguo Testamento. (Nolan, 1981, p. 59)

El pueblo de Israel posteriormente se vio enfrentado a encontrar la manera de expresar el milagro de la liberación de tal manera que se evidenciara la acción directa de Dios, y la respuesta la contiene Éxodo 14, pues para los israelitas, aunque hubiera ocurrido todo de manera natural, en este acontecimiento, como en todos, había intervenido directamente Dios; solo que la liberación los asombró tanto que escribieron varias versiones, desde la fe, de este gran hecho, para mostrar que había sido Dios quien los había liberado.

\section{Conclusiones}

La investigación del milagro del mar lleva a colegir que la exégesis basada en el análisis histórico-crítico tiene su validez en la actualidad, siempre y cuando se tenga presente un acercamiento a la interpretación teológica de las Sagradas Escrituras. No puede dejarse de lado, como bien lo entendió el Concilio Vaticano II, que la biblia ha de ser el alma de la teología, y, consecuentemente, el estudio de la biblia ha de estar transido por la interpretación teológica. La teología sin una fundamentación bíblica puede convertirse en una simple especulación racional, y el estudio de la biblia sin la interpretación teológica puede devenir en un análisis literario infecundo.

Por otra parte, es preciso tener presente que la teología en la actualidad tiene el reto de dilucidar, con el avance de la ciencia, lo que realmente se entiende por milagro o signo, 
pues no hacerlo le está costando una deformación de la imagen de Dios, y ya se sabe que tener imágenes de Dios que no corresponden con la revelada es una de las grandes tentaciones desde el Antiguo Testamento (Cfr. Ex 32).

De igual manera, no se debe olvidar que hay un presupuesto para que un acontecimiento sea milagroso: la fe, y no una fe que está regida por una serie de fórmulas o que pudieran encontrarse en manuales para poder comunicarse con Dios, y así la divinidad escuche y actúe cuando se le pide, sino una fe que des-cubre, des-vela y re-conoce la acción de Dios siempre presente en cada historia particular; una fe que ayuda a tomar conciencia de que Dios sigue trabajando (Cfr. Jn 5:17).

\section{Referencias Bibliográficas}

Al-Arifi, N. S., Lashin, A. A., y Al-Humidan, S. (2012). Migration of local earthquakes in the Gulf of Aqaba, North Red Sea. Earth Sciences Research Journal, 16(1), 35-40. https://bit.ly/2MehMBk

Alexander, T. D. (1995). From Paradise to the Promised Land. An Introduction to the Main Themes of the Pentateuch. Carlisle U.K.: Paternoster Press.

Alonso Schökel, L. (s.f.). Biblia del peregrino (Vol. 1). Estella: Verbo Divino.

Alonso Schökel, A., Mateos, J., Benito, A., Gil Modrego, A., y Múgica, J. A. (Trads.). (1970). Pentateuco: Génesis- Éxodo (Vol. 1). Madrid: Cristiandad.

Álvarez, A. (2002). ¿Cómo cruzaron los israelitas el Mar Rojo?. Cuestiones Teológicas y Filosóficas, 29(72), 407-412.

Auzou, G. (1996). De la salvación al servicio: estudio del libro del Éxodo. Madrid: Fax.

Azaryahu, M. (2005). The beach at the end of the world: Eilat in Israeli popular culture. Social \& Cultural Geography, 6(1), 117-133. https://doi.org/10.1080/1464936052000335008

Batayneh, A. T. (2007). Mapping subsurface formations on the Eastern Red Sea Coast in Jordan using geoelectrical techniques: geological and hydrogeological implications. Earth Sciences Research Journal, 11(2), 97-107. https://bit.ly/2X07d76

Benedicto XVI. Vaticano II. Exhortación Apostólica Postsinodal Verbum Domini. 30 de septiembre de 2010. https://bit.ly/3n3uAaH

Berder, M., Birnbaum, M., Delattre, B., Cousin, H., Déclais, J. L., Etaix, R., Gruson, P. y Meunier, B. (1998). La Pascua y el paso del mar en las interpretaciones judías, cristianas y musulmanas (Éx 12-14) (J. P. Tosaus, Trad.). Estella: Verbo Divino.

Bergoeing, J. P. (2015). Riesgo volcánico en la Península Árabe. Revista Geográfica, (156), 43-52. https://bit.ly/3pD6fKf

Blenkinsopp, J. (1999). El pentateuco: introducción a los cinco primeros libros de la Biblia. Estella: Verbo Divino. 
Borgonovo, G., Balzaretti, C., Barbiero, G., Boschi, G. B., Cardellino, I., Mazzinghi, L., Nobile, M. y Ska, J. L. (2012). Torah e storiografie dellAntico Testamento. Torino: Elledici.

Bultmann, R. (1973). Nuovo testamento e mitología. Brescia: Queriniana.

Campbell, A. F. y O'Brien, M. A. (1993). Sources of the Pentateuch: texts, introductions, annotations. Minneapolis: Fortress Press.

Campbell, A. F. y O'Brien, M. A. (2005). Rethinking the Pentateuch: prolegomena to the Theology of Ancient Israel. Westminster: John Knox Press.

Camus, A. (1973). El mito de Sísifo. (Vol. 2, Obras Completas). México: Aguilar.

Cardona, H. (2002). Los signos en la Biblia: una aproximación bíblico teológica. Cuestiones teológicas y filosóficas, 28(69), 71-115.

Coogan, M. D. (2006). The Old Testament: a historical and literary introduction to the Hebrew Scriptures, Oxford: Oxford University Press.

Couto, A. (2003). Pentateuco: caminho da vida agraciada, Lisboa: Universidade Católica Editora.

De Vaux, R. (1971). Historia antigua de Israel (Vol. 1). Madrid: Cristiandad.

Erdozain, L. (2002). Los milagros. Estudios Eclesiásticos, 77(300), 141-162. https://bit.ly/3pD2LYb

Farmur, A., Levoratti, A., Eugnue, S., y Dungan. (1999). Comentario internacional. Estella: Verbo Divino.

Fretheim, T. E. (1996). The Pentateuch. Nashville: Abingdon Press.

Galvagno, G. y Giuntoli, F. (2014). Dai frammenti alla storia: introduzione al Pentateuco. Torino: Elledici.

García López, F. (2003). El Pentateuco. Estella: Verbo Divino.

Garduño García, M. (2019). Arabia Saudí y las dinámicas de financiarización en Oriente Medio: algunas repercusiones geopolíticas del proyecto Neom en el Mar Rojo. Relaciones Internacionales, (42), 141-156. https://doi.org/10.15366/relacionesinternacionales2019. 42.008

Hyslop, H. (1983). Un método popular para discernir los milagros. Scripta Theologica, 15(1), 143-151. https://doi.org/10.15581/006.15.1.143-152

Levoratti, A, J. (Dir.), Tamez, E. y Richard, P. (Colab.). (2003). Comentario bíblico latinoamericano. Estella: Verbo Divino.

Missimer, T., Hoppe-Jones, C., Jadoon, K., Li, D., y Al-Mashharawi, S. (2014). Hydrogeology, water quality, and microbial assessment of a coastal alluvial aquifer in western Saudi Arabia: potential use of coastal wadi aquifers for desalination water supplies. Hydrogeology journal, 22(8), 1921-1934. https://doi.org/10.1007/s10040-014-1168-3 
Morales, J. (1970). El milagro en la teología contemporánea. Scripta Theologica, 2(1), 195220. https://doi.org/10.15581/006.2.1.195-220

Nolan, A. (1981). “QQuién es este hombre?” Jesús antes del cristianismo. Santander: Sal Terrae.

Pinto, K. (2017). In God's Eyes: the sacrality of the seas in the Islamic cartographic vision. Espacio, tiempo y forma. Serie VII, Historia del arte, (5), 55-79. https://doi.org/10.5944/etfvii.5.2017.18131

Sartre, J. (1985). El existencialismo es un humanismo. Barcelona: Obris, S.A.

Settembrini, M. (2012). Nel Pentateuco: introduzione ai primi cinque libri della Bibbia. Cinisello Balsamo: San Paolo.

Ska, J. (2001). Introducción a la lectura del Pentateuco. Claves para la interpretación de los cinco primeros libros de la Biblia. Estella: Verbo Divino.

Tallet, P. (2017). Tres puertos egipcios en el Mar Rojo durante el período faraónico : una reevaluación de la evidencia. Antiguo Oriente, 15, 175-194. https://bit.ly/2WZZjdW

Tillich, P. (1970). Amor, poder y justicia; análisis ontológicos y aplicaciones éticas. Barcelona: Ariel.

Torres, A. (1986). Creo en Dios Padre: el Dios de Jesús como afirmación plena del hombre. Santander: Sal Terrae.

Torres, A. (1996). Repensar la cristología: sondeos hacia un nuevo paradigma. Estella: Verbo Divino.

Torres, A. (2000). Fin del cristianismo premoderno: retos hacia un nuevo horizonte. Santander: Sal Terrae.

Varo, F. (2016). Pentateuco y libros históricos. Pamplona: EUNSA.

von Rad, G. (1972). Teología del Antiguo Testamento (Vol. 1). Salamanca: Sígueme.

Wood, W. W. (2011). Source of paleo-groundwater in the Emirate of Abu Dhabi, United Arab Emirates: evidence from unusual oxygen and deuterium isotope data. Hydrogeology journal, 19(1), 155-161. https://doi.org/10.1007/s10040-010-0626-9

\section{Para citar este artículo bajo Norma APA 7a ed. \\ Vargas González, C. E. (2020). El signo del mar: una interpretación bíblico-teológica de Éx 14. Cuadernos de teología - Universidad Católica del Norte (En línea), 12, e4296, https://doi.org/10.22199/issn.0719-8175-2020-0011}

Copyright del articulo: @2020 Carlos Vargas

Este es un artículo de acceso abierto, bajo licencia Creative Commons BY 4.0. 